\title{
Macrostomia-preauricular tags-external ophthalmoplegia syndrome
}

INSERM

\section{Source}

INSERM. (1999). Orphanet: an online rare disease and orphan drug data base.

Macrostomia-preauricular tags-external ophthalmoplegia syndrome. ORPHA:83619

Macrostomia-preauricular tags-external ophthalmoplegia syndrome combines

macrostomia or abnormal mouth contour, preauricular tags, uni- or bilateral ptosis and external ophthalmoplegia. It was described in nine members of a Brazilian family. It is a new phenotype belonging to the so-called oculoauriculovertebral spectrum, resulting from a branchial arch anomaly. Transmission is autosomal dominant. 